\title{
Exploring semantic interoperability in e-government interoperability frameworks for intra-African collaboration: a systematic review
}

\author{
Safa M. Yousif Ahmed \\ Sudan University of Science \\ and Technology \\ newsafasudan@gmail.com
}

\author{
Hossana Twinomurinzi \\ University of South Africa \\ twinoh@unisa.ac.za
}

\begin{abstract}
While many African countries have called for ICTbased intra-African collaboration, services, and trade, it is not known whether this call is technically feasible. For such intra-African based collaboration, semantic interoperability would be required between the national e-government systems. This paper reviewed the e-government interoperability frameworks (e-GIFs) of English and Arabic speaking African countries to identify the evidence and conflict approaches to semantic interoperability. The results suggest that only seven African countries have e-GIFs, which have mainly been adopted from the UK's e-Government Metadata Standards (eGMS) and on Dublin's Core metadata (DC). However, many of the e-GIFs, with the exception of Nigeria, have not been contextualized to the local needs. The paper, therefore, concluded that more effort needs to be placed in developing e-GIFs in Africa, with particular emphasis on semantic interoperability, if the dream of intra-African collaboration is to be achieved.
\end{abstract}

\section{Introduction}

One of the fundamental principles of digital government is to maintain a common interpretation of information across all its entities and to its citizens. However, ICT systems are often created in each government entity without consideration of whether this common interpretation will be maintained. When meaning between ICT systems is not maintained, it results in semantic conflicts [34]. The fundamental concept of semantic interoperability is that the enhancement of the application processing, integration and performance is achievable through the rich descriptions of information and behavioral models to ensure the correct meaning of the exchanged information between ICT systems [40]. In a digital government context, semantic interoperability would ensure more efficient services because the ICT systems can communicate meaning with each other through a shared digital government knowledge base, a common model or reference standard [18]. It can, therefore, be argued that an unconscious creation of ICT systems in government entities, without consideration of semantic interoperability, creates deeper division and entrenches the silo effect in government.

Most digital government strategies have an eGovernment Interoperability Framework (e-GIF) or Enterprise Interoperability Architecture (EIA) that provides the basis for a one-stop, fully electronic services platform. These frameworks usually contain the essential prerequisites for linking up services and define how every service definition and deployment ought to be carefully analyzed and clear vly addressed. The service definitions are usually achieved through three main levels; organizational, semantic and technical [30]. Many scholars [5, 28, 38] suggest that while the technical interoperability and integration requirements are fundamental, an effective data sharing model to manage the information shared between ICT systems is the most crucial aspect of achieving the true interoperable cross agencies environment in which seamless e-service provisions can be guaranteed. Semantic interoperability enables such collaboration [11].

In this paper, we attempt to investigate semantic interoperability in the e-GIFs of African countries. There have been growing calls among African countries to leverage the rapid adoption of ICT for closer collaboration and intra-African trade as seen in initiatives such as "Smart Africa" [45]. We posit that in order to achieve such ICT based intra-African collaboration, an emphasis needs to be placed on ensuring that e-GIFs include semantic interoperability. We therefore systematically reviewed the e-GIF frameworks of 26 African countries for their inclusion of semantic interoperability.

The subsequent sections of the paper include Section 2 which focuses on similar related works, Section 3 explains semantic conflicts and their resolving approaches, Section 4 discusses digital government semantic interoperability and Section 5 explains the process of the systematic review. Sections 
6 and 7 present the findings and their discussion. Section 8 presents the conclusions, further research and limitations.

\section{Related works}

There is limited research discussing the comparison of e-GIFs that include African countries. Only a few consider semantic interoperability and none investigate semantic interoperability in the African countries. Table 1 summarizes those related works.

\section{Table 1. Related works}

\begin{tabular}{|c|c|}
\hline Author & Summary \\
\hline $\begin{array}{l}\text { Lisboa et } \\
\text { al [19] }\end{array}$ & $\begin{array}{l}\text { They investigated the existence of interoperability } \\
\text { frameworks in African countries. }\end{array}$ \\
\hline $\begin{array}{l}\text { Rorissa et } \\
\text { al [31] }\end{array}$ & $\begin{array}{l}\text { They analyzed the electronic services provided by } \\
\text { African digital government Websites and made a } \\
\text { comparison of interoperability frameworks of } 30 \\
\text { countries around the world. }\end{array}$ \\
\hline $\begin{array}{l}\text { Lallana et } \\
\text { al [16] }\end{array}$ & $\begin{array}{l}\text { Government interoperability frameworks were } \\
\text { reviewed for selected countries which have a few } \\
\text { African countries among them. }\end{array}$ \\
\hline $\begin{array}{l}\text { Mutula et } \\
\text { al [21] }\end{array}$ & $\begin{array}{l}\text { They compared the status of interoperability between } \\
\text { sub-Saharan African countries against transitional and } \\
\text { developed countries to benchmark the best practices of } \\
\text { the developed countries to assist African countries in } \\
\text { their digital government development. }\end{array}$ \\
\hline $\begin{array}{l}\text { Theochari } \\
\text { s et al } \\
{[40]}\end{array}$ & $\begin{array}{l}\text { They presented the results of an EU funded digital } \\
\text { government project showing how semantic } \\
\text { technologies are adding value by improving and } \\
\text { revolutionizing digital government. }\end{array}$ \\
\hline $\begin{array}{l}\text { Lamharha } \\
\text { r et al [18] }\end{array}$ & $\begin{array}{l}\text { They compared five digital government semantic } \\
\text { driven projects; OntoGov, TerreGov, DIP, } \\
\text { SemanticGov and Access-eGov. They showed how } \\
\text { ontologies and Semantic Web Services (SWS) play a } \\
\text { fundamental role by enabling the exchange of } \\
\text { information, business process and service modeling. }\end{array}$ \\
\hline $\begin{array}{l}\text { Charalabi } \\
\text { dis et al } \\
\text { [6] }\end{array}$ & $\begin{array}{l}\text { They compared the interoperability frameworks of } \\
\text { Australia, Estonia, Germany, Greece, New Zealand, } \\
\text { Belgium, Denmark, United Kingdom and United States } \\
\text { of America for similarities and differences. They then } \\
\text { provided a set of recommendation for countries that are } \\
\text { planning to develop their eGIFs. }\end{array}$ \\
\hline $\begin{array}{l}\text { Ryhänen } \\
\text { et al. [32] }\end{array}$ & $\begin{array}{l}\text { They compared a generic data model used in } \\
\text { governments for semantic interoperability. They } \\
\text { investigated how much these models could support and } \\
\text { enhance semantic interoperability using four features } \\
\text { that have proven to be useful and effective on semantic } \\
\text { interoperability. a) The usage of standard languages } \\
\text { and notation for modeling b) Entities relationships } \\
\text { modeling and describing c) Vocabulary separation for } \\
\text { data exchanges description d) A consensus on using } \\
\text { procedures and methodologies to develop semantic } \\
\text { assets and data models }\end{array}$ \\
\hline $\begin{array}{l}\text { Peristeras } \\
\text { et al [28] }\end{array}$ & $\begin{array}{l}\text { A comprehensive exploratory research of e- } \\
\text { government interoperability initiatives was conducted. } \\
\text { The initiatives were categorized according to owner, } \\
\text { scope and modeling perspective of each project. }\end{array}$ \\
\hline $\begin{array}{l}\text { Fonou et } \\
\text { al [9] }\end{array}$ & $\begin{array}{l}\text { They addressed the limited initiatives to adopt } \\
\text { semantic interoperability technologies in the digital } \\
\text { government domain in sub-Saharan African countries } \\
\text { and then presented a case study of transforming } \\
\text { domain ontology into its digital government processes. } \\
\text { Formal version to be used as an example of how to }\end{array}$ \\
\hline
\end{tabular}

incorporate semantic web technologies successfully in e-governments.

To achieve the intra-African ideal of collaboration, there must exist the ability in the e-GIFs to resolve semantic conflicts. The next section begins with a discussion on semantic conflicts and how they are resolved.

\section{Semantic conflicts between ICT systems}

The rapid evolution of different types of ICTs has resulted in semantic conflicts. Heterogeneous ICT systems have two main different types of semantic conflicts; data and schema levels conflicts. Data level conflicts include different representation or interpretation of the exchanged information caused by the different data models, conceptual models or different naming conventions. Schema level semantic conflicts could occur as a result of logic structures and metadata differences and inconsistencies [22].

In Niemann et al [24], semantic conflicts were illustrated as occurring in ICT systems because of the structural and cultural differences in the organization's different business types, hierarchies, terminologies, process workflows and unique way of doing business. There is, therefore, a need to effectively ensure integration at the semantic level and enable collaboration between the communicating ICT systems [13]. However, most strategic ICT efforts only focus on technical integration at the expense of semantic interoperability [39]. Semantic interoperability enables collaborating systems to exchange and use the information using the correct meaning as well as providing the means and tools for automatic integration and processing of information without the intervention of humans [42].

Semantic conflicts are no different in digital government. Data and schema conflicts can arise when interoperability is not well managed [27]. Data level conflicts are usually caused by the differences in various communicating domains whereas schema level conflicts happen as a result of differences in logical structures [27]. For example, data level conflicts could be the value of the variable "gender" as male and female in one system whereas in another system it is $\mathbf{M}$ and F. For data precision, an example could be the unit used for currency or length. In the spatial domain, different data may be requested according to different contexts such as blood groups, which in some contexts violate privacy and granularity conflicts. Schematic discrepancies occur when detailed information cannot be exchanged due to schematic differences such as different XML schemas [27]. 


\subsection{Approaches to resolving semantic conflicts}

Semantic conflicts must be resolved at the two data and schema levels in order to reach the desirable semantic integration between heterogeneous systems conflict resolution. Any approach considered should take into account the autonomy of the ICT-systems, the scalability of the systems to add or remove ICT systems and to manage participants changes, the ability of the system to compose information from different information systems and location and data format access transparency [2].

According to Banouar et al [2], resolving approaches to achieve semantic interoperability are classified into three main domains :

- Mapping based approach: resolution is achieved by establishing a correspondence between entities, classes, relationships, attributes as well as domain components of the global schema and the collaborating local schemas.

- Query-oriented approach: interpretable languages such as comprehensive expended SQL or logical declarative languages which are used for the identification, locating, transformation and integration of relevance of data according to semantics associated using high order expressions to handle and control the data and metadata [3].

- Intermediary-based approach (mediators): this approach deals with translation services provision to the collaborating systems from different semantic domains using ontologies and shared vocabulary or protocol to communicate. Mediators should be able to coordinate the communicating systems using mappings or rules based on a specific knowledge of a domain.

Broadly speaking, to successfully resolve semantic conflicts ensuring semantic interoperability, all the communicating ICT systems must conform to an agreed authority which manages the semantic contents development using consensus agreed approach methodologies and standards to define a clear meaning for the information exchanged [1].

\section{Semantic interoperability in digital government systems}

During recent years, many governments have created interoperability projects using semantic technologies and solutions. It has become increasingly crucial for governments to help in harmonizing their processes and standardizing their shared information to make their systems more interoperable [35]. Recommending semantic solutions is challenging in government domain due to the various differences in regulations, laws, services, administrative processes and multilingualism [4].

The most important target of all interoperability frameworks in government is to pave the way for a seamless provision of e-services by enabling cross agencies collaboration through a one-stop portal [36]. The development of the interoperability framework is therefore greatly influenced by the approach; whether they are integrated/tightly-coupled, unified or federated/loosely-coupled. These choices in return determine the way the data models are shared [7].

In the context of digital government, semantic technologies and metadata models can greatly contribute to the efficient information sharing in digital government as well as searching and retrieval processes because metadata are used to consume the data released on those platforms. This is achieved by enabling a clearly structured manner of processing and understanding information by machines [20,29].

Ojo et al [25] identify that for government to attain semantic interoperability, three main semantic elements have to be fulfilled; semantic description, semantic mediation and semantic discovery. They further assert that semantic interoperability in government organizations can only be achieved via the ability of their ICT systems to:

- Discover (information discovery)

- Describe (formal description of the shared information)

- Mediate (ability to use and process the received information in the correct intended purpose by all participating) [25]

Semantic description is the most maturely developed aspect of semantic interoperability in many of the national e-GIFs. In semantic description, the description of data and information yields semantic interoperability assets such as dictionaries, controlled vocabularies, taxonomies, thesaurus and ontologies. They are usually developed using formal languages, standards or notations. According to Lamharhar et al [18], representation of digital government, knowledge can be categorized into two groups: metadata and reference data models.

Metadata is data about data in XML/XML schema language and standards [8]. The Dublin Core Metadata standard was the first method used to represent data to create a common format but only at the metadata level. This allowed mapping and exchanging of normative texts in a seamless syntactically interoperable manner between the ICT systems [10,17]. Some examples of metadata usage in government domain are Dublin Core (DC), vCard, Governmental Markup Language (GovML), oeGOV ontologies and ISO 11179 [18]. 
Reference data models ensure semantic interoperability by creating an agreed shared information model that defines the public administration's main concepts, their attributes and relations [32]. Some examples of such models include UK's Government Common Information Model (UKGCIM), Federal enterprise architecture (FEA) model and governance enterprise architecture (GEA) model, data, information and process integration (DIP) government model [18].

Using unified reference models and metadata standards in describing the government knowledge contributes greatly to the ability of interoperating systems [18]. Nonetheless, local and central metadata registries and repositories can dramatically enhance the allocation and discovery of semantic assets such as thesauri, ontologies and taxonomies [36]. Even with good data description and discovery tools, which utilize the registries and repositories, information that is exchanged might face some conflicts during the provision of services between different semantic domains. Semantic mediation takes care of translating and matching different semantic assets, ensuring that interoperable systems collaborate to support public services via a one-stop portal. Semantic mediation is often achieved through the use of clearinghouses and semantic gateways [33].

Most of the recent e-GIF initiatives are modeled using the Service Oriented Architecture (SOA) model, thereby shifting the modeling trends from processbased to service-based [28]. SOA is a loosely coupled approach, which uses a federated approach to collaborate in the provision of services. When web services are used in an open large-scale service environment such as a digital government domain, there are numerous amounts of web services that would have to be discovered and orchestrated according to the service in demand. In such situations, semantic web technologies are used to introduce the semantic web services that are machine interoperable, allowing flexible integration and an adaptive response to changes of the systems $[9,15,23]$.

\section{Intra African digital government services}

The dream of cross-border e-government services would, among others, create opportunities to open up new markets and better information sharing. The true essence of ensuring such collaboration depends on efficient and effective information sharing between all the communicating government systems. Semantic interoperability supports that by ensuring all ICT systems are complying to common standards and data models.

An understanding of semantic interoperability at the national level would help to identify the possibility of intra-African collaboration at an intra continent level.

\section{Methodology}

Systematic reviews are the most rigorous types of study which can be conducted by an investigator embarking on a research [26]. Such rigorousness demands the researcher to acquire certain skills to apply in different situations with different topics and problems and the ability to understand the interrelationship between theory, method and research design; and to successfully integrate them [12].

We conducted a systematic review to explore the eGIFs frameworks of selected African countries and to determine their inclusion of semantic interoperability. Specifically, we sought to investigate how semantic techniques and technologies have been incorporated in the e-GIFs of African countries. To allow a rigorous search, the review process followed Okoli and Schabram's [26] eight steps guide to conduct the review. The steps are:

Identify the purpose: the purpose of the research was to explore e-GIF initiatives in selected African countries and to investigate the inclusion of semantic interoperability. Specifically, the primary research questions were: (1) How many African countries have an e-GIF? (2) For those with an e-GIF, how many satisfied semantic interoperability requirements?

Search strategy and practical screening of literature: the research was done in two phases; firstly, a background literature review was undertaken to understand the concepts and components of semantically based interoperability frameworks and how they were approached by the governments and research initiatives. The second phase was to search for the frameworks that were developed in African countries specifically and see how many aspects of semantic interoperability were covered. The study was carried out based on the available data on the internet and from online databases about African countries. The study focused on 26 African countries, which have their resources in English or Arabic. The focus was based on the researchers' lingual capabilities. Countries that had their documents in French were accordingly excluded. The 26 countries that fell within the research scope were, therefore: Algeria, Botswana, Egypt, Gambia, Ghana, Kenya, Lesotho, Libya, Liberia, Malawi, Mauritius, Morocco, Namibia, Nigeria, Rwanda, Sierra Leone, Seychelles, South Africa, South Sudan, Sudan, Swaziland, Tanzania, 
Tunisia, Uganda, Zambia and Zimbabwe. The second phase was also undertaken in two parts; the first was to use the Google search engine to look for the existence of the countries' digital government master plan or strategy, one-stop-portal website and official documents about the e-GIF. Online databases, Google Scholar, Science Direct, Semantic Scholar, Springer Link, IEEE Xplore and Academia were then used to search again for interoperability frameworks and any other supporting articles, which may contain research initiatives proposing new e-GIFs.

The following search strings were used to look for the interoperability frameworks: "country's name egovernment", "country's name digital government", "country's name e-government framework", "country's name digital/e-government interoperability framework", "country's name digital OR e-government integration framework", "country's name e-government architecture interoperability framework", "country's name semantic interoperability", "semantic interoperability in country's name interoperability framework". "Semantic web technologies in country's name digital OR e-government framework" were then used to search for any supporting articles which might have discussed semantic interoperability.

The inclusion criteria applied to select the supporting papers used for analysis included:

- Official interoperability frameworks reports and documents published by designated government bodies on an official government website and other related websites, regardless of their published date

- Peer-reviewed journals, conferences proceedings, workshop papers, book chapters which explicitly contain, discuss, compare or explore the country's e-GIF and/or semantic interoperability study cases

- Documents written either in English or Arabic

- Documents published or released online between 2012 and 2018. Initially, the decision was to include articles since 2016; however, there was very limited retrieved literature. The decision was therefore made to widen the search to start from 2012. It is assumed that strategic projects often take up to five years before being completed.

The official documents of the country's interoperability frameworks and ICT plans or strategies that were retrieved using Google search were selected without screening because they are fundamental to the study regardless of their issuance date. The results of the supporting articles retrieved from all databases for each country were merged to remove the repeated documents followed by applying the inclusion and exclusion criteria and finally practical screening to keep only the relevant unique articles. The first total number of retrieved articles and documents was 520; removing 82 repeated documents took it down to 438 . Applying the inclusion and exclusion criteria and practical screening, as well as the limitation of the few numbers of the countries, resulted in 10 articles. The excluded articles were removed because in addition to the publication date range criterion, most of them were studying adoption and evaluation of digital government's projects and the majority addressed the technical and organizational interoperability only.

\section{Results}

Seven of the selected African countries have eGIFs; Egypt, Ghana, Mauritius, Morocco, Nigeria, South Africa and Swaziland.

The semantic interoperability was assessed in each of the e-GIFs using five aspects which were found very beneficial in achieving semantic interoperability based on the literature review $[25 ; 28 ; 32 ; 33 ; 41]$. Each eGIF was evaluated to decide if an aspect is covered or not according to the following criteria:

- Semantic interoperability guidelines: an e-GIF should have a clear definition of interoperability and its importance along with methods, procedures and illustrative examples of how to approach it.

- Semantic description languages: an e-GIF should provide unified notations and standards: where the semantic description of semantic assets is based on agreed-upon government-wide specifications and ontologies.

- Semantic assets storage: an e-GIF should show how the collaborating systems store their described semantic assets and provide services to manage their usage and updates. Local and central semantic asset repositories are used for storage services. We consider this criterion is satisfied also in an e-GIF if there exist guidelines to develop semantic repositories.

- Semantic assets, discovery tools or guidelines: an e-GIF should include a mechanism to control the life cycle of a semantic asset. Local and central metadata registries (clearinghouses) are used to manage the life cycle of an asset to track all the operation it might go through such as publishing, pushing into a repository, searching or updating. We consider this criterion satisfied also if there exist some guidelines to develop discovery tools or a clear methodology which enables that.

- Semantic Mediation Tools: an e-GIF should have a mechanism to resolve any semantic conflicts which might occur between the communicating parties. Gateways are used to translate semantic conflicts or differences between the semantic assets given by the clearinghouses - the thing that 
ensures the efficient and correct exchange of information.

The results of evaluating the e-GIFs' semantic interoperability progress based on the above assessment framework are shown in table 2 below; a dot indicates that the e-GIF has covered the semantic aspect.

\section{Table2. Semantic interoperability assessment framework's results}

\begin{tabular}{|c|c|c|c|c|c|}
\hline Country & $\begin{array}{c}\text { Semantic } \\
\text { Interoperability } \\
\text { Guidelines }\end{array}$ & $\begin{array}{c}\text { Semantic } \\
\text { Description } \\
\text { languages, } \\
\text { notations } \\
\text { and } \\
\text { standards }\end{array}$ & $\begin{array}{c}\text { Semantic } \\
\text { assets } \\
\text { Storage / } \\
\text { guidelines }\end{array}$ & $\begin{array}{c}\text { Semantic } \\
\text { Discovery } \\
\text { tools or } \\
\text { guide lines }\end{array}$ & $\begin{array}{c}\text { Semantic } \\
\text { Mediation } \\
\text { Tools }\end{array}$ \\
\hline Egypt & $\bullet$ & $\bullet$ & & & \\
\hline Ghana & $\bullet$ & $\bullet$ & & & \\
\hline Kenya & $\bullet$ & $\bullet$ & & & \\
\hline Mauritius & $\bullet$ & $\bullet$ & & & \\
\hline Moracco & $\bullet$ & $\bullet$ & $\bullet$ & & \\
\hline Nigeria & $\bullet$ & $\bullet$ & & & \\
\hline South Africa & $\bullet$ & $\bullet$ & & & \\
\hline Swaziland & $\bullet$ & $\bullet$ & & & \\
\hline
\end{tabular}

\section{Discussion}

The eventual number of reviewed articles reveals the limited amount of literature that focuses on semantic interoperability in the government domain of African countries context.

Only seven $(26 \%)$ out of the 26 African countries have developed e-GIFs. The early adopters were Mauritius, Egypt, Ghana and South Africa. The late adopters are Morocco and Swaziland.

The results suggest that all the e-GIFs, regardless of the level of details, have demonstrated efforts to set a consensus on formal standards and guidelines addressing the three aspects of achieving interoperability: organizational, semantic and technical. It was only Egypt where no evidence was found to indicate how their semantic interoperability was supported. The paper, therefore, considers that the Egyptian e-GIF was developed using a pure technical driven approach.

Countries such as Ghana, Mauritius, Nigeria and Swaziland identified that the development of their frameworks was based on benchmarking against best practice and accordingly adopted UK's e-Government Metadata Standards (eGMS) and Dublin Core Metadata. Their adopted standards suggest that little effort was made to modify or enhance the best practice. This suggests that there might be challenges later when the semantic interoperability needs to be deployed within the national context.

The findings show that semantic interoperability guidelines and semantic description languages, notations and standards are the most satisfying aspects in all e-GIFs except for Egypt. The Ghana e-GIF describes 80 entities depicting their relationships using UML notations. However, the absence of semantic assets published publicly for collaboration in the other e-GIFs shows the need to improve the understanding of the importance of semantic description languages and notations in building up a common knowledge base.

South Africa adopted The Open Archive Initiative Protocol for Metadata Harvesting 2.0 and recommended it as a metadata harvesting approach. This approach has clear guidelines to implement both metadata repositories and harvesters that can be considered as a guideline to allow sharing and reusing of semantic assets between the digital government's systems.

Nigeria in its newest version of e-GIF has specified steps to be followed by its ministries, departments and agencies (MDAs). The steps articulate how MDAs should achieve semantic interoperability for cross agencies service provision through the creation and sharing of semantic assets, which describes their digital government's services. Nigeria adopted a bottom-up approach in which they established a methodology to create and store the controlled vocabularies for each cross-agency service and they are planning to eventually populate a standard national ICT-enabled service vocabulary for the whole domain. The Nigeria e-GIF satisfies the semantic assets storage by providing guidelines to create and store service's semantic assets in the national ICT-enabled service vocabulary.

\section{Conclusion}

Investigating the inclusion of semantic interoperability in the e-GIFs of English and Arabic speaking African countries was the main purpose of this paper. The final results revealed only seven African countries have publicly available e-GIFs. The inclusion of semantic interoperability was based on the existence of the following five indicators: semantic interoperability guidelines, semantic description languages, semantic assets storage, semantic assets, discovery tools or guidelines and semantic mediation tools.

This paper contributes to theory in identifying five measures that can be used as sufficient benchmarks for the existence of a well-defined semantic interoperable e-GIF and as a basis for achieving regional collaboration. The assessment framework is important 
to achieving the dream of an ICT based intra-African collaboration.

In conclusion, the paper identifies that intra-African collaboration may only be successful if semantic interoperability is better defined in each of the e-GIFs. The opportunity for such collaboration exists since most of the countries do not have a well-defined e-GIF and can therefore easier develop their e-GIFs based on common data models and standards.

\section{Limitations, recommendations and future work}

The paper was limited in its focus on English and Arabic speaking African countries. A wider perspective that includes other dominant languages such as Swahili, French or Portuguese would provide a more holistic perspective. The paper also did not consider semantic interoperability across different dialects (languages) as may be the case in Africa.

For future research, we identify the opportunity to create an intra-African semantic interoperability framework that appreciates local national needs while at the same time enabling interoperability with the egovernment systems of other African countries.

\section{References}

[1] Akatkin, Y.M., E.D. Yasinovskaya, M.G. Bich, and A. V Shilin, "Methods of Semantic Integration in Distributed Information Systems : Challenges of Application", 2016, pp. 80-84.

[2] Banouar, O., and S. Raghay, "Comparative study of the systems of semantic integration of information: A survey", Proceedings of IEEE/ACS International Conference on Computer Systems and Applications, AICCSA 2(05478), 2015, pp. 1-8.

[3] Benharzallah, S., O. Kazar, and G. Caplat, "Intelligent query processing for semantic mediation of information systems", Egyptian Informatics Journal 12(3), 2011, pp. 151-163.

[4] Bettahar, F., C. Moulin, and J.-P. Barthès, "Towards a Semantic Interoperability in an eGovernment Application", Electronic Journal of $e$ Government 7(3), 2009, pp. 209-226.

[5] Bountouri, L., "Metadata interoperability in public sector information", Journal of Information Science 35(2), 2009, pp. 204-231.

[6] Charalabidis, Y., F. Lampathaki, and D. Askounis, "A Comparative Analysis of National Interoperability Frameworks", Americas Conference on Information Systems (AMCIS), Americas Conference on Information Systems (AMCIS) at AIS Electronic Library (AISeL) (2009), 1-10.
[7] Chen, D., and G. Doumeingts, "Architectures for enterprise integration and interoperability: Past, present and future", Computers in Industry , ELSEVIER 59, 2008, pp. 647-659.

[8] Davies, J., S. Harris, C. Crichton, A. Shukla, and J. Gibbons, "Metadata standards for semantic interoperability in electronic government", Proceedings of the 2nd International Conference on Theory and Practice of Electronic Governance, 2008, pp. 67-75.

[9] Fonou Dombeu, J. V, and M. Huisman, "Semantic-driven e-government: A case study of formal representation of government domain ontology", IST-Africa Conference Proceedings, 2011, 2011, pp. 1-9.

[10] García-Castro, R., and A. Gómez-Pérez, "Perspectives in Semantic Interoperability", The SemanticWeb Research and Applications 8th Extended SemanticWeb Conference, 2011, pp. 16.

[11] Guijarro, L., "Semantic interoperability in eGovernment initiatives", Computer Standards \& Interfaces 31(1), 2009, pp. 174-180.

[12] Hart, C., "The Literature review in research", In Doing a literature review - Releasing the Social Science Research Imagination. SAGE Publication, 1998, 25.

[13] He, W., and L. Da Xu, "Integration of Distributed Enterprise Applications : A Survey", IEEE TRANSACTIONS ON INDUSTRIAL INFORMATICS 10(1), 2014, pp. 35-42.

[14] Kalvet, T., M. Toots, A.F. van Veenstra, and R. Krimmer, "Cross-border e-Government Services in Europe", Proceedings of the 11th International Conference on Theory and Practice of Electronic Governance - ICEGOV'18, 2018, pp. 69-72.

[15] Khan, A.N., S. Asghar, and S. Fong, "Framework of integrated semantic Web services and ontology development for telecommunication industry", Journal of Emerging Technologies in Web Intelligence 3(2), 2011, pp. 110-119.

[16] Lallana, E.C., e-Government Interoperability: A Review of Government Interoperability Frameworks in Selected Countries, 2007.

[17] Lamharhar, H., A Semantic modelling approach for $e$ - government domain A Semantic modelling approach for e-government domain, Rabat, Morocco, 2016.

[18] Lamharhar, H., D. Chiadmi, and L. Benhlima, "How semantic technologies transform e-government domain A comparative study and framework", Transforming Government: People, Process and Policy 8(1), 2014, pp. 49-75.

[19] Lisboa, A., and D. Soares, "E-government Interoperability Frameworks: A Worldwide Inventory", Procedia Technology 16, 2014, pp. 638- 
648.

[20] Milic, P., N. Veljkovic, and L. Stoimenov, "Comparative analysis of metadata models on egovernment open data platforms", IEEE Transactions on Emerging Topics in Computing 6750(c), 2018, pp. $1-13$.

[21] Mutula, M.S., "Comparison of sub-Saharan Africa's e-government status with developed and transitional nations", Information Management \& Computer Security 16(3), 2014, pp. 235-250.

[22] Naiman, C.F., and A.M. Ouksel, "A classification of semantic conflicts in heterogeneous database systems A Classification of Semantic Conflicts in Heterogeneous Database Systems", JOURNALOFORGANIZATIONALCOMPUTING 5:2, 1995, pp. 167-193.

[23] Ni, J., X.L. Zhao, and L.J. Zhu, "A semantic Web service-oriented architecture for enterprises", Research and Practical Issues of Enterprise Information Systems II, Vol 1 254, 2008, pp. 535-544.

[24] Niemann, B., R. Morris, and H. Riofrio, Introducing Semantic Technologies and the vision of the Semantic Web, 2008.

[25] Ojo, A., T. Janowski, and E. Estevez, "Semantic Interoperability Architecture for Electronic Government", Electronic Government(Section 2), 2009, pp. 63-72.

[26] Okoli, C., "A Guide to Conducting a Standalone Systematic”, 37, 2015.

[27] Peristeras, V., N. Loutas, S.K. Goudos, and K. Tarabanis, "A conceptual analysis of semantic conflicts in pan- European e-government services", Journal of Information Science 34(6), 2008, pp. 877-891.

[28] Peristeras, V., K. Tarabanis, and S.K. Goudos, "Model-driven eGovernment interoperability: A review of the state of the art", Computer Standards and Interfaces 31(4), 2009, pp. 613-628.

[29] Petrušić, D., M. Segedinac, and Z. Konjović, "Semantic modelling and ontology integration of the open government systems", Tehnicki vjesnik Technical Gazette 23(6), 2016, pp. 1631-1641.

[30] Ray, D., U. Gulla, S.S. Dash, and M.P. Gupta, "A critical survey of selected government interoperability frameworks", Transforming Government: People, Process and Policy 5(2), 2011, pp. 114-142.

[31] Rorissa, A., and D. Demissie, "An analysis of African e-Government service Websites", Government Information Quarterly 27(2), 2010, pp. 161-169.

[32] Ryhänen, K., T. Päivärinta, and P. Tyrväinen, "Generic data models for Semantic e- Government interoperability: Literature Review", Innovation and the Public Sector 21, 2014, pp. 106-119.

[33] Sanchez, A., A. Ojo, T. Janowski, and E. Estevez, "Semantic Interoperability Middleware -
Cases and applications in Electronic Government", 2008 Third International Conference on Digital Information Management, 2008, pp. 800-805.

[34] Sandoval-Almazán, R., L.F. Luna-Reyes, D.E. Luna-Reyes, J.R. Gil-García, and S. Picazo-Vela, "Networked Government and Interoperability", Public Administration and Information Technology 16(Building Digital Government Strategies: Principles and Practices), 2017, pp. 51-63.

[35] Scholl, H.J., H. Kubicek, R. Cimander, and R. Klischewski, "Process integration, information sharing, and system interoperation in government: A comparative case analysis", Government Information Quarterly 29(3), 2012, pp. 313-323.

[36] Shukair, G., N. Loutas, V. Peristeras, and S. Sklarß, "Towards semantically interoperable metadata repositories: The Asset Description Metadata Schema", Computers in Industry 64(1), 2013, pp. 10-18.

[37] Smart Africa, Smart Africa Strategic Vision, 2013.

[38] Sourouni, A.M., G. Kourlimpinis, S. Mouzakitis, and D. Askounis, "Towards the government transformation: An ontology-based government knowledge repository", Computer Standards and Interfaces 32(1-2), 2010, pp. 44-53.

[39] Sugumaran, V., and J.A. Gulla, Applied Semantic Web Technologies, Taylor \& Francis Group, 2012.

[40] Theocharis, S., and G. Tsihrintzis, "Semantic Web technologies in e-government", ... of Science, Engineering and Technology 6(4), 2012, pp. 12371244.

[41] Vitvar, T., V. Peristeras, and K. Tarabanis, "Semantic technologies for e-government", Semantic Technologies for E-Government, 2010, pp. 1-321.

[42] Yang, S., J. Guo, and R. Wei, "Semantic interoperability with heterogeneous information systems on the internet through automatic tabular document exchange", Information Systems 69, 2017, pp. 195-217.

[43] Zillmer, S. (Spatial F., F. (Spatial F. Holstein, T. (EureConsult) Stumm, et al., Cross-border Public Services ( CPS ) Targeted Analysis, 2018.

[44] "Welcome to Smart Africa", http://smartafrica.org/

[45] "The Smart Africa Manifesto - Smartafrica", $2017 . \quad$ https://smartafrica.org/resources/publicdocuments/article/the-smart-africa-manifesto 